\title{
The Integrative Weaning Index in Elderly ICU Subjects
}

\author{
Leandro M Azeredo PT MSc, Sérgio N Nemer PT PhD, Carmen SV Barbas MD PhD, \\ Jefferson B Caldeira PT MSc, Rosângela Noé MSc, Bruno L Guimarães PT, and \\ Célia P Caldas RN PhD
}

\begin{abstract}
BACKGROUND: With increasing life expectancy and ICU admission of elderly patients, mechanical ventilation, and weaning trials have increased worldwide. METHODS: We evaluated a cohort with 479 subjects in the ICU. Patients younger than $18 \mathrm{y}$, tracheostomized, or with neurologic diseases were excluded, resulting in 331 subjects. Subjects $\geq 70$ y old were considered elderly, whereas those $<70$ y old were considered non-elderly. Besides the conventional weaning indexes, we evaluated the performance of the integrative weaning index (IWI). The probability of successful weaning was investigated using relative risk and logistic regression. The Hosmer-Lemeshow goodness-of-fit test was used to calibrate and the $\mathrm{C}$ statistic was calculated to evaluate the association between predicted probabilities and observed proportions in the logistic regression model. RESULTS: Prevalence of successful weaning in the sample was $83.7 \%$. There was no difference in mortality between elderly and non-elderly subjects $(P=.16)$, in days of mechanical ventilation $(P=.22)$ and days of weaning $(P=.55)$. In elderly subjects, the IWI was the only respiratory variable associated with mechanical ventilation weaning in this population $(P<.001)$. CONCLUSIONS: The IWI was the independent variable found in weaning of elderly subjects that may contribute to the critical moment of this population in intensive care. Key words: mechanical ventilation; weaning; elderly. [Respir Care 2017;62(3):333-339. (C) 2017 Daedalus Enterprises]
\end{abstract}

\section{Introduction}

With advances in several areas of medicine, the number of elderly people has been increasing worldwide. ${ }^{1}$ Admis-

\footnotetext{
Mr Miranda de Azeredo and Dr Nogueira Nemer are affiliated with the Critical Care Department, Hospital da Polícia Militar de Niterói, Rua Martins Torres 245, Santa Rosa, Niterói, Rio de Janeiro, Brazil. Dr Nogueira Nemer and Mr Braga Caldeira are affiliated with the UNIGRANRIO University Post-Graduate Program associated with the Hospital de Clínicas de Niterói. Rua José de Souza Herdy, 1160 Bairro Vinte e Cinco de Agosto, Duque de Caxias, Rio de Janeiro, Brazil. Dr Silva Valente Barbas is affiliated with the Pulmonary and Critical Care Department, Hospital das Clínicas de São Paulo, Avenida Dr. Enéas de Carvalho Aguiar, sétimo andar, sala 7079, São Paulo, Brazil. Mr Braga Caldeira and Mr Guimarães are affiliated with the Critical Care Department, Hospital de Clínicas de Niterói, Rua La Salle 12, Centro, Niterói, Rio de Janeiro, Brazil. Ms Noé is affiliated with the Biostatistics Department, Universidade Federal do Rio de Janeiro, Rio de Janeiro, Brazil. Dr Pereira Caldas is affiliated with the Post-Graduate Program, Hospital Universitário Pedro Ernesto, Avenida Boulevard 28 de Setembro, 77 Vila Isabel, Rio de Janeiro, Brazil.
}

The authors have disclosed no conflicts of interest. sion of elderly patients with acute respiratory failure to emergency departments is increasingly common, ${ }^{1,2}$ and it is hard to find an ICU that has no predominance of elderly patients. Among the several causes of acute respiratory failure in the elderly, community-acquired pneumonia is one of the most common. ${ }^{3}$ In addition, surgical indication for elderly patients ${ }^{4}$ is often observed, with specific functional implications for this population when admitted to the ICU receiving mechanical ventilation.

Although some studies concluded that age alone cannot represent a strong predictor for mortality, it can determine treatment intensity ${ }^{5}$ and ICU admission..$^{6,7}$ Although age has influence on mortality, ${ }^{8}$ it seems that the severity of acute disease at admission has more effect on mortality in

\footnotetext{
Correspondence: Leandro M Azeredo PT MSc, Critical Care Department, Hospital da Polícia Militar de Niterói, Rua Martins Torres 245, Santa Rosa, Niterói, Rio de Janeiro, CEP: 24240-705, Brazil. E-mail: azeredo.lm@gmail.com.
}

DOI: $10.4187 /$ respcare. 04524 
comparison with age alone. ${ }^{1}$ It seems that there is no consensus about the influence of age on mortality associated with mechanical ventilation. ${ }^{9}$ However, regarding weaning from mechanical ventilation, it seems that elderly subjects with community-acquired pneumonia are associated with difficult weaning. ${ }^{3}$

According to the Sixth International Consensus Conference on Intensive Care Medicine, ${ }^{10}$ patients who meet satisfactory weaning criteria should be considered ready for weaning. To improve the performance of the mechanical ventilator weaning, new indexes ${ }^{11,12}$ have been proposed and applied to different populations. ${ }^{13}$

The objective of this study is to evaluate the variables associated with successful weaning from mechanical ventilation in elderly subjects, observing traditional predictors and the integrative weaning index (IWI). For this purpose, we compared the weaning outcome in elderly ( $\geq 70 \mathrm{y}$ old) and non-elderly subjects ( $<70$ y old $)$.

\section{Methods}

This was a prospective cohort study, conducted from a database set up for a study of predictors of weaning in 3 general ICUs of the Hospital de Clínicas de Niterói (Rio de Janeiro, Brazil). The study was conducted from September 2004 to January 2008, and we performed a second analysis, regarding elderly and non-elderly subjects. It was approved by the ethics committee of Pedro Ernesto University Hospital and registered as an International Standard Randomized Controlled Trial under number 92117906.

Patients younger than $18 \mathrm{y}$ old, with neurological and/or neuromuscular diseases, with $<24 \mathrm{~h}$ receiving mechanical ventilation, and/or tracheostomized were excluded from the study. Three hundred thirty-one subjects who had been receiving mechanical ventilation for $>24 \mathrm{~h}$ were included in the study. After that, we separated subjects younger than 70 y old (non-elderly subjects) from those who were $\geq 70$ y old (elderly subjects).

Informed consent was obtained from each subject, whenever possible, or from the subject's next of kin. The ventilators used were the Evita 2 (Dräger, Lübeck, Germany). Discontinuation from mechanical ventilation was attempted when the physician in charge judged that the subject was ready to be weaned, according to the following criteria: the cause for starting mechanical ventilation had been resolved or at least improved; body temperature was $<38.5^{\circ} \mathrm{C}$; hemoglobin was $\geq 8 \mathrm{~g} / \mathrm{dL}$; and no dose or a minimal dose of vasoactive or sedative drugs was administered. $\mathrm{A}_{\mathrm{aO}_{2}}$ of $\geq 60 \mathrm{~mm} \mathrm{Hg}$ or $\mathrm{S}_{\mathrm{aO}_{2}}$ of $\geq 90 \%$, with a $\mathrm{F}_{\mathrm{IO}_{2}}$ of $\leq 0.4$ and PEEP of $\leq 8 \mathrm{~cm} \mathrm{H}_{2} \mathrm{O}$ were other criteria to be met. A spontaneous breathing trial (SBT) was then evaluated by means of a 2-h T-piece.

\section{QUICK LOOK}

\section{Current knowledge}

The concern with the high prevalence of elderly patients in ICUs, who frequently require mechanical ventilation, is the high morbidity and mortality factor in this population. However, the association of age with weaning and hospital mortality is unclear, with doubts persisting about its existence, regardless of other risk factors, such as comorbidities, disease severity, and duration of mechanical ventilation.

\section{What this paper contributes to our knowledge}

Age did not influence weaning outcome. The integrative weaning index was the only independent variable to predict the success of weaning in a sample of elderly patients. Thus, it may be an important predictor in evaluating weaning in this population.

The static compliance of the respiratory system $\left(\mathrm{C}_{\mathrm{RS}}\right)$ was measured during volume control ventilation through the same method used by Aboussouan et al ${ }^{14}$ after assessing the digital display of the ventilator to verify the pressure-time curve without inspiratory efforts of the subjects. An inspiratory hold for $0.5-1.0 \mathrm{~s}$ was used to measure the compliance. $C_{R S}$ was calculated by dividing the $V_{T}$ by the difference between inspiratory plateau pressure and PEEP. A bedside spirometer (RM121, Ohmeda, Tokyo, Japan) was attached to the expiratory valve of the ventilator to check the expiratory tidal volume measurement before each calculation of $\mathrm{C}_{\mathrm{RS}}$.

Before the weaning trial, all subjects were being ventilated in pressure support ventilation $8-10 \mathrm{~cm} \mathrm{H}_{2} \mathrm{O}$ and PEEP $5 \mathrm{~cm} \mathrm{H}_{2} \mathrm{O}$. Tracheal airway occlusion pressure $\left(\mathrm{P}_{0.1}\right)$ was measured by the software of the Evita 2, at pressure support $7 \mathrm{~cm} \mathrm{H}_{2} \mathrm{O}$. The tracheal $\mathrm{P}_{0.1}$ value was obtained from the average of 3 consecutive measurements with intervals of $15 \mathrm{~s}^{15,16}$

A sample of arterial blood to analyze the $\mathrm{S}_{\mathrm{aO}_{2}}$ and the $\mathrm{P}_{\mathrm{aO}_{2}} / \mathrm{F}_{\mathrm{IO}_{2}}$ was collected at pressure support $7 \mathrm{~cm} \mathrm{H} \mathrm{H}_{2} \mathrm{O}$, PEEP $5 \mathrm{~cm} \mathrm{H} \mathrm{H}_{2} \mathrm{O}$, and $\mathrm{F}_{\mathrm{IO}_{2}}$ 0.35. During the first minute after discontinuation from mechanical ventilation, spontaneous minute volume and respiratory rate were measured with a bedside spirometer (RM121, Ohmeda) attached to the airway. The spontaneous $\mathrm{V}_{\mathrm{T}}$ was calculated by dividing minute volume by breathing frequency (f), and the $f / V_{T}$ ratio was calculated by dividing $\mathrm{f}$ by $\mathrm{V}_{\mathrm{T}}$ (in $\mathrm{L}$ ). ${ }^{17}$

The indexes were measured by the respiratory physiotherapists before the SBTs. The decision to return to mechanical ventilation was made by the physician in charge, who was completely blind to the study and to the results of 
the indexes evaluated, based on the signs of poor tolerance incorporated into our daily routine.

Weaning was considered successful if spontaneous breathing was sustained for $>48 \mathrm{~h}$ after extubation. ${ }^{10}$ During the 2-h period of SBT, tolerance was continuously evaluated by the physician in charge. When the patient remained stable after the 2-h period of SBT, the endotracheal tube was removed.

The trial was stopped when at least one of the following poor tolerance criteria was present: $\mathrm{S}_{\mathrm{aO}_{2}}<90 \%$ and $\mathrm{P}_{\mathrm{aO}}$ $<60 \mathrm{~mm} \mathrm{Hg}$ with $\mathrm{F}_{\mathrm{IO}_{2}}<0.5$, or $\mathrm{S}_{\mathrm{aO}_{2}}<88 \%$ and $\mathrm{P}_{\mathrm{aO}_{2}}$ $<55 \mathrm{~mm} \mathrm{Hg}$ with $\mathrm{F}_{\mathrm{IO}_{2}}<0.5$ in subjects with COPD; $\mathrm{P}_{\mathrm{aCO}_{2}}>50 \mathrm{~mm} \mathrm{Hg}$ (or increased by $\geq 8 \mathrm{~mm} \mathrm{Hg}$ in subjects with COPD); arterial $\mathrm{pH}$ of $\leq 7.33$ or decreased by $\geq 0.07$; f $>38$ breaths $/ \mathrm{min}$ or increased by $50 \%$ for $\geq 5 \mathrm{~min}$; heart rate of $>140$ beats/min or a sustained increase or decrease of $>20 \%$; systolic blood pressure of $>180 \mathrm{~mm} \mathrm{Hg}$ or $<90 \mathrm{~mm} \mathrm{Hg}$; or in the presence of agitation, diaphoresis, disorientation, or depressed mental status. A clearly audible cough and adequate mental status were requirements for subjects to be considered ready for extubation. ${ }^{18}$

Weaning failure was determined if one of the following criteria occurred: failed SBT; re-intubation and/or resumption of ventilator support within $48 \mathrm{~h}$ following successful extubation; or death within $48 \mathrm{~h}$ following extubation. ${ }^{10}$ Patients who died within $48 \mathrm{~h}$ after extubation were previously returned to the ventilator and were not terminally weaned. The distinction between weaning failure (inability to tolerate spontaneous breathing without ventilatory support) and extubation failure (inability to tolerate removal of the translaryngeal tube) was taken into account, ${ }^{18}$ although for results and statistical analysis considerations, all extubation failures were also regarded as weaning failures.

To evaluate the predictive performance of IWI, we compared it with the $f / \mathrm{V}_{\mathrm{T}}$ ratio, which was shown to be the most accurate predictor of failure and success in weaning from mechanical ventilation in the study by Yang and Tobin. ${ }^{17} \mathrm{We}$ also compared the IWI with the following parameters: $\mathrm{P}_{\mathrm{aO}_{2}} / \mathrm{F}_{\mathrm{IO}_{2}}$, which represents an important index to evaluate oxygenation; tracheal $\mathrm{P}_{0.1}$, which is an estimate of neuromuscular drive and is considered to be an important indicator of successful weaning, mainly in subjects with $\mathrm{COPD}^{15}$; and the product of tracheal $\mathrm{P}_{0.1}$ and $\mathrm{f} / \mathrm{V}_{\mathrm{T}}$ ratio $\left(\mathrm{P}_{0.1} \times \mathrm{f} / \mathrm{V}_{\mathrm{T}}\right)$, which has shown more specificity compared with its components, ${ }^{16}$ beyond $\mathrm{f}, \mathrm{V}_{\mathrm{T}}$, and $\mathrm{C}_{\mathrm{RS}}$.

The IWI uses 3 essential parameters that lend themselves to easy measurement and are independent of the subjects' cooperation. It evaluates, in a single equation, respiratory mechanics, oxygenation, and respiratory pattern, through $\mathrm{C}_{\mathrm{RS}}, \mathrm{S}_{\mathrm{aO}_{2}}$, and $\mathrm{f} / \mathrm{V}_{\mathrm{T}}$, respectively, $\mathrm{IWI}=\mathrm{C}_{\mathrm{RS}} \times \mathrm{S}_{\mathrm{aO}_{2}} /\left(\mathrm{f} / \mathrm{V}_{\mathrm{T}}\right)$.
Because we evaluated exactly the same subjects analyzed in the study of Nemer et al ${ }^{11}$ and adopted a threshold value according to the receiver operating characteristic curve, the cutoff point of the IWI index calculated for successful weaning in the range $\geq 70 \mathrm{y}$ and in the range $<70 \mathrm{y}$ is better than or equal to 25 .

\section{Statistical Analysis}

Categorical variables were analyzed by the chi-square test. Numeric variables were analyzed by the Student $t$ test. The chances of successful weaning were investigated using relative risk and logistic regression. The process of the selection factor logistic regression was at $5 \%$. The Hosmer-Lemeshow goodness-of-fit test was used to calibrate and the $\mathrm{C}$ statistic was calculated to evaluate the association between predicted probabilities and observed proportions in the logistic regression model. $P$ values of $<.05$ were considered significant. The statistical analysis was performed using the SAS 9.0 software package (SAS Institute, Cary, North Carolina).

\section{Results}

During the evaluation period, 479 patients received mechanical ventilation in our ICUs. After applying the exclusion criteria, 331 subjects who had been receiving mechanical ventilation for $>24 \mathrm{~h}$ were included in the study, whereas the remaining 148 were not (Fig. 1).

Among the 331 evaluated subjects, we found 155 elderly subjects and 176 non-elderly. In the total population, weaning failure was observed in 54 (16.3\%), and mortality in 17 of 331 subjects $(5.1 \%$, including 10 re-intubated subjects; 4 died in-hospital). The etiology of acute respiratory failure, with its respective percentage regarding the population, is described in Table 1.

The prevalence of successful weaning in the total population was $83.7 \%$. There was no difference in prevalence of successful weaning between elderly and non-elderly subjects $(86.4 \%$ vs $80.7 \%, P=.16)$. On the other hand, APACHE II (Acute Physiology and Chronic Health Evaluation II) score and mortality were higher in elderly subjects $(16.9 \pm 5.8$ vs $15.3 \pm 5.2, P=.009 ; 9.7 \%$ vs $1.1 \%$, $P=.002)$.

There was no difference between elderly and non-elderly subjects regarding days receiving mechanical ventilation $(9.2 \pm 8.6 \mathrm{~d}$ vs $9.1 \pm 6.7 \mathrm{~d}, P=.22)$. There was also no difference in the weaning duration between elderly and non-elderly subjects $(2.8 \pm 2.6 \mathrm{~d}$ vs $2.6 \pm 2.0 \mathrm{~d}$, $P=.55)$. The analysis of the outcome variables by sample and age is described in Table 2 .

In the group with age range $\geq 70 \mathrm{y}$, the quality indicators were: sensitivity $97.6 \%$ (CI 94.9-100\%), specificity 96.7\% (CI 90.2-100\%), positive predictive value 99.2\% 


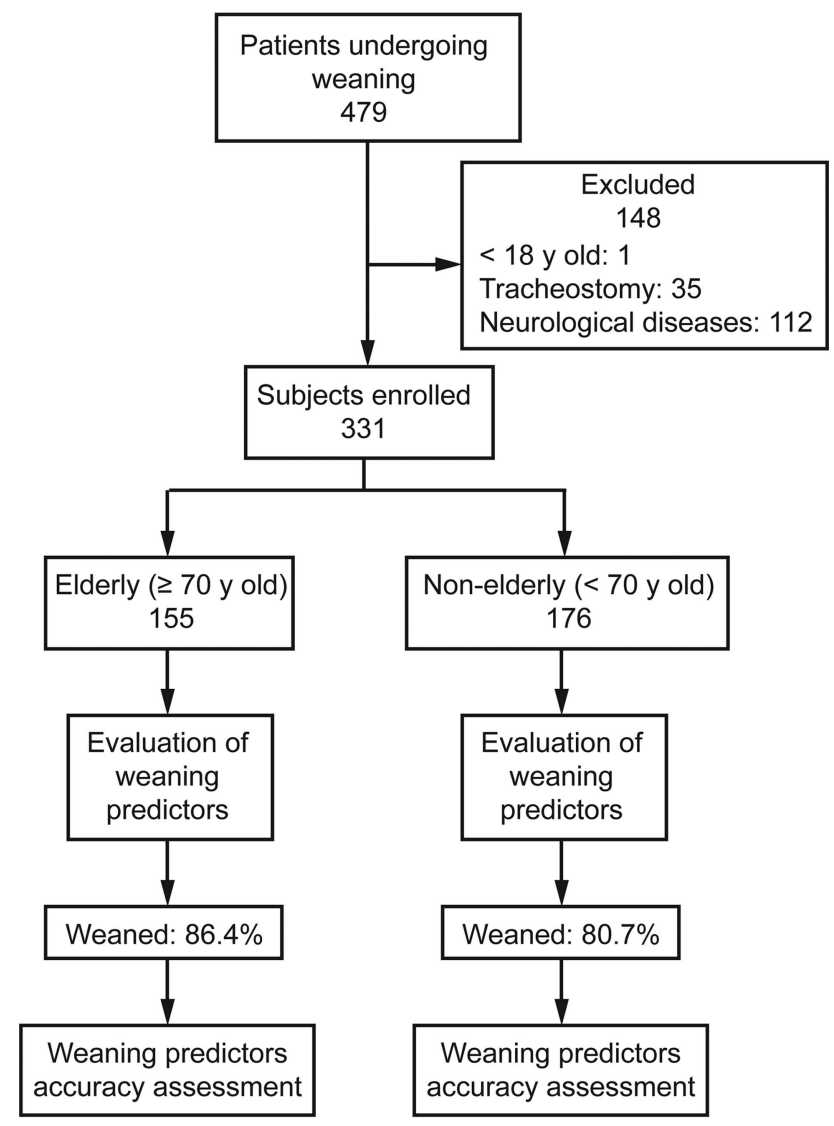

Fig. 1. Flow chart.

Table 1. Etiology and Population

\begin{tabular}{lc}
\hline \hline \multicolumn{1}{c}{ Etiology } & $n(\%)$ \\
\hline COPD & $98(29.6)$ \\
Pneumonia & $68(20.54)$ \\
Postoperative & $63(19.03)$ \\
Sepsis & $39(11.78)$ \\
ARDS & $25(7.55)$ \\
Trauma without brain injury & $11(3.32)$ \\
Acute pulmonary edema & $10(3.02)$ \\
Miscellaneous & $17(5.13)$ \\
Total & $331(100)$ \\
\hline
\end{tabular}

(CI 97.6-100\%), negative predictive value 90.6\% (CI 80.5$100 \%$ ), accuracy $97.4 \%$ (CI 94.9-99.9\%), positive likelihood ratio $29.3 \%$, and negative likelihood ratio $0.02 \%$. In the group with age range $<70 \mathrm{y}$, the quality indicators were: sensitivity $96.1 \%$ (CI 93.0-99.1\%), specificity $91.7 \%$ (CI 80.6-100\%), positive predictive value $98.6 \%$ (CI 96.8$100 \%$ ), negative predictive value $78.6 \%$ (CI 63.4-93.8\%), accuracy $95.5 \%$ (CI 92.4-98.5\%), positive likelihood ratio $11.5 \%$, and negative likelihood ratio $0.04 \%$.

The IWI presented the highest relative risk for successful weaning among the analyzed variables in the 2 samples (elderly and non-elderly subjects): 10.6 and 4.60, respectively. The analysis of the respiratory variables according to the results by age is described in Table 3 .

Simultaneously analyzing the variables in the elderly population, according to the logistic regression, we found that only an IWI of $\geq 25$ ( $P<.001)$ was significant for predicting weaning success of the elderly (Table 4$)$. Analyzing the variables simultaneously, according to the logistic regression, in the non-elderly population, it was observed that an IWI of $\geq 25(P<.001)$ and APACHE II score of $\leq 17(P=.003)$ were significant in predicting success in this population. The other variables showed no independent contribution, at the level of 5\%, in predicting a successful response in the study population (Table 4).

The IWI presented a high predictive value $(97.2 \%)$ in the elderly population, with a CI ranging from 91.2 to 99.1\%. However, combined with the APACHE II, this range decreases significantly, expressing greater confidence. Therefore, we can say that the IWI is an essential predictor of weaning in the elderly population (Table 5).

\section{Discussion}

In an observational study, Nemer et al ${ }^{11}$ evaluated a new IWI. In this study, threshold values were determined in 115 subjects and then prospectively validated in an additional 216 subjects. The IWI was the most accurate weaning predictor, followed by the $\mathrm{f} / \mathrm{V}_{\mathrm{T}}$ ratio. ${ }^{11}$ Our study analyzed the IWI and predictive performance in elderly subjects because they represent the majority of ICU admissions ${ }^{1,2,6,7,17-19}$ and may be at a high risk of mortality. ${ }^{9,17}$

In a multi-center, prospective, cohort study performed in Brazil, a total of 773 adult subjects were admitted to 45 ICUs. ${ }^{9}$ Age, comorbidities, associated organ failure, and ARDS, among other factors, were associated with hospital mortality. ${ }^{8}$ Survivors were younger than non-survivors (mean age 58 vs 69 y old, $P<.001$ ). ${ }^{8}$ The epidemiological study of Walden et al ${ }^{19}$ evaluated 1,166 subjects admitted to 102 ICUs across 19 countries. Subjects older than $64 \mathrm{y}$ of age accounted for $>50 \%$ of cases. ${ }^{19}$ The study of Quintana et $\mathrm{al}^{20}$ evaluated 2,487 subjects with COPD admitted to the emergency department. Age was highly associated with mortality and admission to the ICU and emergency department, whereas the mean age was $>72 \mathrm{y} .{ }^{20}$

Although the mean age of the evaluated subjects in our study was $>64 \mathrm{y}$, there was not a prevalence of elderly subjects; in fact, without including the 11 multiple trauma patients, who were non-elderly, we found exactly $50 \%$ each of elderly and non-elderly subjects, and we did not find a significant difference between successful and unsuccessful weaning or in days of mechanical ventilation between elderly and non-elderly sub- 
Table 2. Analysis of the Outcome Categorical Variables by Sample and by Age

\begin{tabular}{|c|c|c|c|c|}
\hline Variable/Category & Total & Age $\geq 70 y$ & Age $<70$ y & $P$ \\
\hline Result, $n(\%)$ & & & & .16 \\
\hline Success & $277(83.7)$ & $125(80.7)$ & $152(86.4)$ & \\
\hline Failure & $54(16.3)$ & $30(19.4)$ & $24(13.6)$ & \\
\hline Death & $17(5.1)$ & $15(9.7)$ & $2(1.1)$ & \\
\hline Evolution, $n(\%)$ & & & & .002 \\
\hline Discharge & $277(83.7)$ & $125(80.7)$ & $152(86.4)$ & \\
\hline Return & $37(11.2)$ & $15(9.7)$ & $22(12.5)$ & \\
\hline Days of mechanical ventilation, mean $\pm \mathrm{SD} /$ median $\mathrm{d}$ & $9.1 \pm 7.6 / 7$ & $9.2 \pm 8.6 / 6$ & $9.1 \pm 6.7 / 7$ & .22 \\
\hline Days of weaning, mean $\pm \mathrm{SD}$ /median $\mathrm{d}$ & $2.7 \pm 2.3 / 2$ & $2.8 \pm 2.6 / 2$ & $2.6 \pm 2.0 / 2$ & .55 \\
\hline APACHE II, mean $\pm \mathrm{SD} /$ median & $16.0 \pm 5.6 / 15$ & $16.9 \pm 5.8 / 16$ & $15.3 \pm 5.2 / 14$ & .009 \\
\hline
\end{tabular}

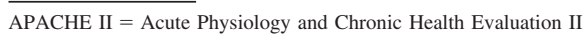

Table 3. Analysis of the Respiratory Variables According to the Results by Age

\begin{tabular}{|c|c|c|c|c|c|c|c|c|}
\hline \multirow{2}{*}{ Variable } & \multicolumn{4}{|c|}{ Age $\geq 70 y$} & \multicolumn{4}{|c|}{ Age $<70 y$} \\
\hline & Success $(\%)$ & Failure (\%) & RR & $95 \% \mathrm{CI}$ & Success $(\%)$ & Failure (\%) & $\mathrm{RR}$ & $95 \% \mathrm{CI}$ \\
\hline $\mathrm{P}_{\mathrm{aO}_{2}} / \mathrm{F}_{\mathrm{IO}_{2}} \geq 255$ & 59.2 & 46.7 & 1.11 & $0.94-1.30$ & 63.2 & 16.7 & 1.30 & $1.13-1.50$ \\
\hline $\mathrm{C}_{\mathrm{RS}} \geq 30$ & 80.8 & 23.3 & 1.83 & $1.38-2.43$ & 84.2 & 29.2 & 1.62 & $1.25-2.10$ \\
\hline IWI $\geq 25$ & 97.6 & 3.3 & 10.6 & $3.60-31.1$ & 96.1 & 8.3 & 4.60 & $2.26-9.36$ \\
\hline $\mathrm{P}_{0.1} \leq 3.1$ & 78.4 & 36.7 & 1.53 & $1.19-1.97$ & 77.0 & 20.8 & 1.48 & $1.21-1.81$ \\
\hline $\mathrm{f} \leq 29$ & 72.8 & 33.3 & 1.43 & $1.16-1.77$ & 68.4 & 20.8 & 1.33 & $1.14-1.56$ \\
\hline $\mathrm{V}_{\mathrm{T}} \geq 320$ & 76.8 & 23.3 & 1.67 & $1.31-2.14$ & 73.7 & 29.2 & 1.34 & $1.13-1.60$ \\
\hline $\mathrm{f} / \mathrm{V}_{\mathrm{T}} \times \mathrm{P}_{0.1} \leq 270$ & 80.0 & 33.3 & 1.64 & $1.25-2.14$ & 77.0 & 16.7 & 1.52 & $1.24-1.86$ \\
\hline $\mathrm{f} / \mathrm{V}_{\mathrm{T}} \leq 100$ & 81.6 & 23.3 & 1.87 & $1.40-2.51$ & 78.3 & 25.0 & 1.47 & $1.20-1.81$ \\
\hline \multicolumn{9}{|c|}{$\begin{array}{l}\text { Significant } P<.001 \text {, except for } \mathrm{P}_{\mathrm{aO}_{2}} / \mathrm{F}_{\mathrm{IO}_{2}} \text { on age } \geq 70 \mathrm{y} \\
\mathrm{RR}=\text { relative risk } \\
\mathrm{C}_{\mathrm{RS}}=\text { compliance of the respiratory system } \\
\mathrm{IWI}=\text { integrative weaning index } \\
\mathrm{P}_{0.1}=\text { airway-occlusion pressure } 0.1 \mathrm{~s} \text { after the start of inspiration against an occluded airway } \\
\mathrm{f}=\text { breathing frequency } \\
\mathrm{V}_{\mathrm{T}}=\text { tidal volume }\end{array}$} \\
\hline
\end{tabular}

jects. However, we observed a significant difference regarding mortality, which was higher in elderly subjects $(9.7 \%$ vs $1.1 \%, P=.002)$.

Clinical judgment is not enough to predict weaning outcome accurately (50\% positive predictive value and $67 \%$ negative predictive value). ${ }^{19,21}$ Although the SBT presents a positive weaning predictive value of $85 \%, 1915 \%$ of the patients who can complete an SBT require re-intubation in the following $48 \mathrm{~h}$ after extubation. This indicates that there are patients who tolerate short SBTs but not longer ones. Although research has shown the SBT has provided significant predictive value for weaning from mechanical ventilation, there is still a portion of patients for which it fails. In the study by Frutos-Vivar et $\mathrm{al}^{22}$ extubation failure occurred in 121 of the 900 subjects (13.4\%) who completed the SBT.

Among the routinely measured clinical variables, $f / V_{T}$ ratio, positive fluid balance $24 \mathrm{~h}$ before extubation, and the presence of pneumonia at the beginning of mechanical ventilation were found to be the best predictors of extubation failure..$^{22}$ This fact reinforces the hypothesis that not only the clinical evaluation but also the evaluation of weaning indexes (such as the IWI and $\mathrm{f} / \mathrm{V}_{\mathrm{T}}$ ratio) can be helpful. Weaning indexes that evaluate one single function have generally presented poor accuracy. ${ }^{17,23}$

On the other hand, the IWI, which can evaluate multiple essential functions, such as $\mathrm{f} / \mathrm{V}_{\mathrm{T}}$, compliance of the respiratory system, and oxygenation, presented higher predictive performance in a general population in the study of Nemer et $\mathrm{al}^{11}$ and in the current study too. The IWI has been cited in several review studies, ${ }^{11,24-27}$ described as highly accurate, ${ }^{11,25,26}$ and recommended by the Brazilian guidelines on mechanical ventilation. ${ }^{24}$ Besides these advantages, the IWI can be measured regardless of the subject's cooperation. ${ }^{11}$ According to the logistic regression in the total sample, only the IWI $(\geq 25, P<.001)$ and the APACHE II ( $\leq 17, P=.003)$ were found to be independent predictors of success in weaning. In elderly subjects, 
Table 4. Logistic Regression to the Success of Weaning by Age

\begin{tabular}{lrrrrr}
\hline \hline Variable Significant & Coefficient & SE & $P$ & RR & 95\% CI \\
\hline Age $\geq 70$ y & & & & & \\
$\quad$ Intercept & -2.2687 & 0.606 & $<.001$ & & \\
IWI $\geq 25$ & 7.0727 & 1.173 & $<.001$ & $1,179.3$ & $118-11752$ \\
Age $<70$ y & & & & & \\
Intercept & -3.1147 & 1.035 & .003 & & \\
IWI $\geq 25$ & 6.0547 & 1.187 & $<.001$ & 426.1 & $41.6-4364$ \\
APACHE II $\leq 17$ & 3.4249 & 1.159 & .003 & 30.7 & $3.2-298$ \\
& & & & & \\
\hline RR $=$ relative risk & & & & & \\
IWI $=$ integrative weaning index & & & & & \\
APACHE II $=$ Acute Physiology and Chronic Health Evaluation II & & \\
SE $=$ standard error & & & & & \\
\end{tabular}

Table 5. Estimated Probability of Success According to the Logistic Model by Age Group

\begin{tabular}{lccrc}
\hline \hline & IWI $\geq 25$ & APACHE II $\leq 17$ & EP $(\%)$ & \multicolumn{1}{c}{$95 \%$ CI } \\
\hline Age $\geq 70$ & No & & 9.4 & $3.06-25.4$ \\
& Yes & & 99.2 & $94.5-99.9$ \\
Age $<70$ & No & No & 4.3 & $0.58-25.2$ \\
& No & Yes & 57.7 & $27.5-83.1$ \\
& Yes & Yes & 95.0 & $81.8-98.8$ \\
& Yes & No & 99.8 & $98.0-100$
\end{tabular}

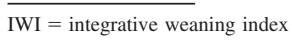

APACHE II = Acute Physiology and Chronic Health Evaluation II

$\mathrm{EP}=$ estimated probability

only the IWI independently predicted successful weaning accurately $(P<.001)$.

The main limitations of the study are as follows. Although $\mathrm{C}_{\mathrm{RS}}$ can be measured during discontinuation from mechanical ventilation, ${ }^{14,17}$ this not always an easy task to perform during the weaning process, because the patient's inspiratory effort during an assisted breath may interfere with the inspiratory plateau pressure measurement. In our study, we minimized this limitation by observing the digital display of the pressure-time inspiratory plateau curve, thus avoiding respiratory cycles that revealed clear inspiratory efforts of the subjects.

In our study, the IWI was measured with a fixed $\mathrm{F}_{\mathrm{IO}_{2}}$ of $35 \%$ to avoid variations in $\mathrm{S}_{\mathrm{aO}_{2}}$ due to $\mathrm{F}_{\mathrm{IO}_{2}}$ variations, only to standardize the study protocol. Further studies must be performed to test the IWI accuracy in a wider range of $\mathrm{F}_{\mathrm{IO}_{2}}$ values, but we believe that the IWI can be measured with any $\mathrm{F}_{\mathrm{IO}_{2}}$ value $<40-50 \%$.

The measurement of the tracheal $\mathrm{P}_{0.1}$ can be a limitation of the study because $\mathrm{P}_{0.1}$ is traditionally measured through an esophageal balloon. However, tracheal $\mathrm{P}_{0.1}$ can be accurately measured at bedside ${ }^{25}$ through a new generation of software coupled to microprocessor mechanical ventilators, thus being an easier way to assess $\mathrm{P}_{0.1}$ than the esophageal balloon technique.
This was a single-center study. Whether the results can be generalized to other ICUs is still to be determined.

\section{Conclusions}

Satisfactory oxygenation, $\mathrm{C}_{\mathrm{RS}}$, and breathing pattern, reflected by the IWI $\geq 25$, generally lead to successful weaning in elderly subjects. A large majority of the ICU population is composed of elderly patients, and the IWI, which had previously shown high accuracy in a general population, now demonstrates strong accuracy in elderly subjects as well.

The IWI was the only independent variable found in the weaning of elderly subjects that is able to contribute to the critical moment of this population in intensive care. We believe that the IWI may be the most accurate index to predict weaning outcome.

\section{REFERENCES}

1. Roch A, Wiramus S, Pauly V, Forel JM, Guervilly C, Gainnier M, Papazian L. Long-term outcome in medical patients aged 80 or over following admission to an intensive care unit. Critical Care 2011; 15(1):R36.

2. Delerme S, Ray P. Acute respiratory failure in the elderly: diagnosis and prognosis. Age Ageing 2008;37(3):251-257.

3. Fujii M. Factors influencing weaning from mechanical ventilation in elderly patients with severe pneumonia. Geriatr Gerontol Int 2012(2); 12:277-283.

4. Niemeyer-Guimarães M, Condoroglo MS, Almada-Filho CM. Course of functional status in elderly patients after coronary artery bypass surgery: 6-month follow up. Geriatr Gerontol Int 2016;16(6):737746.

5. Boumendil A, Somme D, Garrouste-Orgeas M, Guidet B. Should elderly patients be admitted to the intensive care unit? Intensive Care Med 2007;33(7):1252-1262.

6. Boumendil A, Aegerter P, Guidet B. Treatment intensity and outcome of patients aged 80 and older in intensive care units: a multicenter matched-cohort study. J Am Geriatr Soc 2005;53(1):88-93.

7. Garrouste-Orgeas M, Timsit JF, Montuclard L, Colvez A, Gattolliat O, Philippart F, et al. Decision-making process, outcome and 1-year quality of life of octogenarians referred for intensive care unit admission. Intensive Care Med 2006;32(7):1045-1051.

8. Garrouste-Orgeas M, Boumendil A, Pateron D, Aergerter P, Somme D, Simon T, et al. Selection of intensive care unit admission criteria for patients aged 80 years and over and compliance of emergency and intensive care unit physicians with the selected criteria: an observational, multicenter, prospective study. Crit Care Med 2009; 37(11):2919-2928.

9. Azevedo LCP, Park M, Salluh JIF, Rea-Neto A, Souza-Dantas VC, Varaschin P, Oliveira MC, et al. Clinical outcomes of patients requiring ventilatory support in Brazilian intensive care units: a multicenter, prospective, cohort study. Crit Care 2013;17(2):R63.

10. Boles JM, Bion J, Connors A, Herridge M, Marsh B, Melot C, et al. Weaning from mechanical ventilation. Eur Respir J 2007;29(5):10331056.

11. Nemer SN, Barbas CSV, Caldeira JB, Cárias TH, Santos RG, Almeida LC, et al. A new integrative weaning index of discontinuation from mechanical ventilation. Crit Care 2009;13(5):R152. 


\section{InTEgRative WeAning IndeX In ElDERLy ICU SubJects}

12. de Souza LC, Guimarães FS, Lugon JR. Evaluation of a new index of mechanical ventilation weaning: the timed inspiratory effort. J Intensive Care Med 2015;30(1):37-43.

13. de Souza LC, Guimarães FS, Lugon JR. The timed inspiratory effort: a promising index of mechanical ventilation weaning for patients with neurologic or neuromuscular diseases. Respir Care 2015;60(2): 231-238.

14. Aboussouan LS, Lattin CD, Anne VV. Determinants of time-toweaning in a specialized respiratory care unit. Chest 2005;128(5): 3117-3126.

15. Sassoon CS, Te TT, Mahutte CK, Light RW. Airway occlusion pressure. An important indicator for successful weaning in patients with chronic obstructive pulmonary disease. Am Rev Respir Dis 1987;135(1):107-113.

16. Sassoon CS, Mahutte CK. Airway occlusion pressure and breathing pattern as predictors of weaning outcome. Am Rev Respir Dis 1993; 148(4 Pt 1):860-866.

17. Yang KL, Tobin MJ. A prospective study of indexes predicting the outcome of trials of weaning from mechanical ventilation. N Engl J Med 1991;324(21):1445-1450.

18. Epstein SK. Decision to extubate. Intensive Care Med 2002;28(5): 535-546.

19. Walden AP, Clarke GM, McKechnie S, Hutton P, Gordon AC, Rello $\mathrm{J}$, et al. Patients with community acquired pneumonia admitted to European intensive care units: an epidemiological survey of the Genosept cohort. Crit Care 2014;18(2):R58.
20. Quintana JM, Esteban C, Unzurrunzaga A, Garcia-Gutierrez S, Gonzalez N, Barrio I, et al. Predictive score for mortality in patients with chronic obstructive pulmonary disease exacerbations attending hospital emergency department. BMC Med 2014;12:66.

21. Garland A, Olafson K, Ramsey CD, Yogendran M, Fransoo R. Epidemiology of critically patients in intensive care units: a populationbased observational study. Crit Care 2013;17(5):R212.

22. Frutos-Vivar F, Ferguson ND, Esteban A, Epstein SK, Arabi Y, Apezteguía C, et al. Risk factors for extubation failure in patients following a successful spontaneous breathing trial. Chest 2006;130(6): 1664-1671.

23. Nemer SN, Barbas CSV, Caldeira JB, Guimarães B, Azeredo LM, Gago R, Souza PC. Evaluation of maximal inspiratory pressure, tracheal occlusion pressure and its ratio in the weaning outcome. J Crit Care 2009;24(3):441-446.

24. Brazilian Association of Critical Care Medicine and Brazilian Society of Pneumology and Tisiology. Brazilian recommendations of mechanical ventilation 2013 part 2. J Bras Pneumol 2014;40(5):458486.

25. Nemer SN, and Barbas CSV. Predicting parameters for weaning from mechanical ventilation. J Bras Pneumol 2011;37(5):669-679.

26. El-Baradey GF, El-Shmaa NS, Ganna SA. Can integrative weaning index be a routine predictor for weaning success? Indian J Crit Care Med 2015;19(12):703-707.

27. Govil D, Gupta S. Integrative weaning index: new kids on the block. Indian J Crit Care Med 2015;19(12):701-702. 